\title{
Assessment of Imaging Findings in Inflammatory Breast Disease by Ultrasound
}

\author{
SAHAR M. EL-FEKY, M.D.; HEBA ALLAH M.Y. EL-NAGGAR, M.D. and NOURHAN N.S. DEGHIDY, M.Sc.
}

The Department of Radiology, Faculty of Medicine, Ain Shams University

\begin{abstract}
Background: Inflammatory breast disorders include a wide array of underlying causes, ranging from common benign infection, noninfectious inflammation and inflammation resulting from underlying breast malignancy. Mastitis refers to inflammation of the breast parenchyma, often presenting with pain, heat and redness that may be a debilitating illness with prolonged morbidity. It may also present with a wide array of other nonspecific symptoms, which may lead to delayed diagnosis and inappropriate treatment.
\end{abstract}

Aim of Study: To discuss imaging findings in inflammatory breast disease by ultrasound.

Patients and Methods: This was a prospective study which was carried out at Ain Shams University Hospitals; the study was conducted on 100 women with inflammatory breast diseases referred to the Radiology Department and Surgical Outpatient's Clinics.

Results: Echogenic edematous fat lobules of the studied group show that; $30(30.0 \%)$ were negative and $70(70 \%)$ were positive, interstitial edema; 24 (24.0\%) were negative and $76(76 \%)$ were positive, defined collections; $68(68.0 \%)$ were negative and 32 (32\%) were positive.

Lymph node enlargement; 54 (54.0\%) were negative and $46(46.0 \%)$ were positive. There was lymph node enlargement for only 45 (31 cases show reactive lymph nodes oval in shape with preserved shape and hilum and 14 cases show suspicious lymph nodes with cortical thickening and eccentric hilum). Follow-up by u/s and histopathology of the studied group show that $93(93.0 \%)$ were resolved and $7(7.0 \%)$ were IDC by histopathology.

Conclusion: Ultrasound plays a fundamental role in the diagnostic work up of mastitis patients. An ideal ultrasound should ensure an accurate diagnosis, guide for interventional procedures whenever necessary and should be used to monitor adequate management by short term follow-up studies along the course of therapy.

Key Words: Inflammatory breast disease - Assessment of imaging findings - Ultrasound.

Correspondence to: Dr. Nourhan N.S. Deghidy, E-Mail: magdynourhan811@gmail.com

\section{Introduction}

MASTITIS refers to inflammation of the breast parenchyma, often presenting with pain, heat and redness that may be a debilitating illness with prolonged morbidity [1].

It may also present with a wide array of other nonspecific symptoms that may lead to delayed diagnosis and inappropriate treatment. Broadly, inflammatory disorders of the breast can be divided into three categories: Infectious mastitis, noninfectious mastitis and mastitis related to underlying malignancy [2] .

Infectious mastitis encompasses breast-specific and nonspecific forms of infections whether primary or complicating already present breast pathologies. Patients in this group usually present with fulminant inflammatory manifestations and are usually treated with antibiotics, hot fomentations, and various breast drainage procedures [3]

Acute mastitis is usually a bacterial infection and is seen most commonly in the postpartum period while chronic mastitis is a disease of unknown etiology that results in the dilatation of large-sized and intermediate-sized ducts with a surrounding inflammatory infiltrate of lymphocytes and plasma cells [4].

Non-infectious forms of mastitis encompasses another group of aseptic or chemical inflammatory breast disorders that do not necessarily occur during lactation, and thus do not usually present with fulminant inflammatory signs and do not usually resolve with antibiotics. Microbial infection may trigger some forms as periductal mastitis or complicate others as diabetic mastopathy [5] 
Any nonlactating female patient presenting with inflammatory breast symptoms that fail to respond to antibiotic therapy should be advised to go for both a mammography and US examination immediately followed by a punch biopsy from the skin and aspiration from the subdermal lymphatics to exclude any possibility of IBC [6].

Clinical mastitis is characterized by signs of inflammation in the mammary gland including hyperemia, pain, and increased gland size and density. These symptoms may be accompanied or not by systemic signs, such as fever or depression [3].

IBC is an invasive aggressive disease with high rate of metastasis at diagnosis [7]. On ultrasound, subareolar mastitis tends to show mixed solidcystic lesions or collections, however inflammatory breast cancers are more likely to show solid mass lesions [8]

Radiological imaging is more advantageous than clinical examination in evaluating skin thickening as it allows accurate delineation of its extent, measurement and comparison to surrounding skin and contralateral breast [9] .

Subcutaneous edema is easily evaluated using Doppler US, revealing diffuse increase in thickening and echogenicity of the subcutaneous tissue and later accumulation of fluid in the subcutaneous tissue [10].

Hyperemia (increased vascularity) of the breast tissue is another sign of inflammation, this can be evaluated using Doppler US, revealing increased arterial and venous structures [11].

Lactiferous duct abnormalities such as duct dilatation, thickened walls and presence of contents within the ducts should be investigated as some inflammatory conditions are related to lactiferous duct involvement [12].

Aim of the work:

The study aimed to discuss imaging findings in inflammatory breast disease by ultrasound.

\section{Patients and Methods}

Type of study: A prospective study.

Study setting: Ain Shams University Hospitals. 2021).
Study population: Patients with prolonged clinical signs of mastitis referred to the Radiology Department and Surgical Outpatient's Clinics.

\section{Selection criteria:}

Inclusion criteria: Patients presenting with clinical signs of mastitis including redness, hotness, and focal or diffuse swelling of the breast with or without generalized constitutional symptoms with or without palpable breast masses.

Exclusion criteria: Patients presenting with other sole mammary manifestations, for example, palpable mass lesions or nipple discharge.

Sampling method: Convenient sample.

Sample size: 100 female patients (age was ranged between $16.0-67.0$ years with mean \pm S.D. $36.20 \pm 14.12$ years).

Study procedure: Written informed consent is obtained from all patients. All patients are subjected to complete medical history and full clinical examination. Real-time gray-scale and color Doppler sonography is performed using a Siemens Medical Solutions Elegra or Antares unit with an $8-12 \mathrm{MHz}$ linear-array transducer. US reports should confirm (positive finding) or exclude (negative finding) the presence of the following: Echogenic edematous fat lobules, interstitial edema, ill-defined or well defined collections, retroareolar duct system dilatation, thickened skin (>2mm) and its measurement, masses and confirm their cystic or solid nature, abscess cavities, fistulous tracts, lymph node enlargement and its character: US follow-up after a course of antibiotic therapy will be performed for indicated cases to ensure condition amelioration, according to the imaging findings recorded with US they will be classified into benign and malignant forms of mastitis. Reference standard of diagnosis is histopathology after core or surgical biopsy, as well as follow-up studies for lesions for typical signs of simple mastitis. Histopathology or complete resolution after complete medical treatment results will be correlated with the imaging findings of US.

Main outcome measures: Calculation of sensitivity, specificity, PVP, PVN and accuracy.

Ethical considerations: The study is approved from the Ethical Committee of the Department of Radiology, Faculty of Medicine, Ain Shams University.

Data management and analysis: The collected data is coded, tabulated, and statistically analyzed 
using SPSS program (Statistical Package for Social Sciences).

\section{Statistical analysis of the data:}

Data were fed to the computer and analyzed using IBM SPSS software package version 20.0. (Armonk, NY: IBM Corp) qualitative data were described using number and percent. Quantitative data were described using range (minimum and maximum), mean, and standard deviation, median and Interquartile Range (IQR).

\section{Results}

Data were fed to the computer and analyzed using IBM SPSS software package version 20.0. (Armonk, NY: IBM Corp) qualitative data were described using number and percent. Quantitative data were described using range (minimum and maximum), mean, standard deviation, median and Interquartile Range (IQR).

Descriptive analysis of the studied cases according to age was ranged between 16.0-67.0 years with mean \pm S.D. $36.20 \pm 14.12$ years (Table 1).

Table (1): Descriptive analysis of the studied cases according to age $(n=100)$.

\begin{tabular}{rrrr}
\hline & Min-Max. & Mean \pm SD & Median (IQR) \\
\hline Age (years) & $16.0-67.0$ & $36.20 \pm 14.12$ & $33.50(23.0-47.0)$ \\
\hline
\end{tabular}

Descriptive analysis of the studied cases according to lactation, echogenic edematous fat lobules, interstitial edema and defined collection (Table 2) show the following:

Table (2): Distribution of the studied cases according to different parameters $(n=100)$.

\begin{tabular}{lcccc}
\hline & \multicolumn{2}{c}{ Negative } & \multicolumn{2}{c}{ Positive } \\
\cline { 2 - 5 } & No. & $\%$ & No. & $\%$ \\
\hline Lactating & 73 & 73.0 & 27 & 27.0 \\
Echogenic edematous fat lobules & 30 & 30.0 & 70 & 70.0 \\
Interstitial edema & 24 & 24.0 & 76 & 76.0 \\
Defined collections & 68 & 68.0 & 32 & 32.0 \\
\hline
\end{tabular}

Table (2) show lactating of the studied cases were negative in $73(73.0 \%)$ and were positive in $27(27.0 \%)$, echogenic edematous fat lobules; 30 (30.0\%) were negative and $70(70 \%)$ were positive, interstitial edema; $24(24.0 \%)$ were negative and $76(76 \%)$ were positive, defined collections; 68 $(68.0 \%)$ were negative and $32(32 \%)$ were positive.

Descriptive analysis of the studied cases according to retro areolar duct system dilatation, turbid contents and thickened skin (Table 3) show the following:

Table (3): Distribution of the studied cases according to different parameters $(n=100)$.

\begin{tabular}{lcc}
\hline & No. & $\%$ \\
\hline Retro areolar duct system dilatation: & & \\
$\quad$ Negative & 44 & 44.0 \\
$\quad$ Positive & 56 & 56.0 \\
Containing turbid contents: & & \\
$\quad$ Negative & 80 & 80.0 \\
$\quad$ Positive & 20 & 20.0 \\
Thickened skin: & & \\
$\quad$ Negative & 52 & 52.0 \\
$\quad$ Positive & 48 & 48.0 \\
\hline
\end{tabular}

Table (3) show that retro areolar duct system dilatation of the studied cases was negative in 44 (44.0\%) and positive in $56(56.0 \%)$.

Then as regard the content; $80 \%$ has no turbid content, and $20 \%$ has a turbid content, also, the table shows that $52.0 \%$ had no thickened skin, while $48 \%$ had thickened skin.

Descriptive analysis of the studied cases according to presence or absence of masses (Table 4) show the following:

Table (4): Distribution of the studied cases according to masses $(n=100)$.

\begin{tabular}{lcc}
\hline Masses & No. & $\%$ \\
\hline Negative & 93 & 93.0 \\
Positive & 7 & 7.0 \\
\hline
\end{tabular}

Table (4) show masses of the studied group; $93(93.0 \%)$ has no masses and $7(7.0 \%)$ has masses.

Descriptive analysis of the studied cases according to abscess cavities and fistulous tracts (Table 5) show the following:

Table (5): Distribution of the studied cases according to abscess cavities and fistulous tracts $(n=100)$.

\begin{tabular}{llllll}
\hline & \multicolumn{2}{c}{ Negative } & & \multicolumn{2}{c}{ Positive } \\
\cline { 2 - 3 } \cline { 5 - 6 } \cline { 5 - 6 } & No. & $\%$ & & No. & $\%$ \\
\hline Abscess cavities & 53 & 53.0 & & 47 & 47.0 \\
Fistulous tracts & 100 & 100.0 & & 0 & 0.0 \\
\hline
\end{tabular}

Table (5) show abscess cavities and fistulous tracts of the studied group; at abscess cavities; $53(53.0 \%)$ were negative and $47(47.0 \%)$ were positive, at fistulous tracts; $100(100.0 \%)$ were negative. 
Descriptive analysis of the studied cases according to lymph node enlargement (Table 6) show the following:

Table (6): Distribution of the studied cases according to lymph node enlargement $(n=100)$.

\begin{tabular}{|c|c|c|}
\hline & No. & $\%$ \\
\hline \multicolumn{3}{|l|}{ Lymph node enlargement: } \\
\hline - Negative & 54 & 54.0 \\
\hline - Positive & 46 & 46.0 \\
\hline \multicolumn{3}{|l|}{ Lymph node enlargement with $(n=45)$ : } \\
\hline $\begin{array}{l}\text { - Reactive lymph nodes (oval in shape with } \\
\text { preserved shape and hilum) }\end{array}$ & 31 & 68.8 \\
\hline $\begin{array}{l}\text { - Suspicious lymph nodes (cortical thickening } \\
\text { and eccentric hilum) }\end{array}$ & 14 & 31.2 \\
\hline
\end{tabular}

Table (6) show lymph node enlargement of the studied group that $54(54.0 \%)$ were negative and $46(46.0 \%)$ were positive. There was lymph node enlargement with for only 45 (31 cases show reactive lymph nodes (oval in shape with preserved shape and hilum) and 14 cases show suspicious lymph nodes (cortical thickening and eccentric hilum).

Descriptive analysis of the studied cases according to follow-up by $\mathrm{u} / \mathrm{s}$ and histopathology (Table 7) show the following:
Table (7): Distribution of the studied cases according to follow-up by $\mathrm{u} / \mathrm{s}$ and histopathology $(\mathrm{n}=100)$.

\begin{tabular}{lll}
\hline Follow-up by u/s and histopathology & No. & $\%$ \\
\hline Resolved & 93 & 93.0 \\
IDC by histopathology & 7 & 7.0 \\
\hline
\end{tabular}

Table (7) show follow-up by u/s and histopathology of the studied group that 93 (93.0\%) were resolved and 7 (7.0\%) were IDC by histopathology.

Descriptive analysis of ultrasonography imaging sensitivity, specificity, PPV and NP V in inflammatory breast disease.

Table (8): Diagnostic value of imaging findings in inflammatory breast disease by ultrasound.

\begin{tabular}{lll}
\hline Static & \multicolumn{1}{c}{ Value } & \multicolumn{1}{c}{$95 \%$ CI } \\
\hline Sensitivity & $82.3 \%$ & $75.29 \%-100 \%$ \\
Specificity & $90.7 \%$ & $29.04 \%-96.33 \%$ \\
Positive Predictive Value (PPV) & $86.67 \%$ & $40.78 \%-84.61 \%$ \\
Negative Predictive Value (NPV) & $87.6 \%$ & $66.3 \%-95.45 \%$ \\
\hline
\end{tabular}

Table (8) shows the ultrasonography imaging sensitivity was $82.3 \%$, specificity was $90.7 \%$, NPV was $87.7 \%$ and PPV was $87.6 \%$ with accuracy of $90 \%$ to assess for respectability.
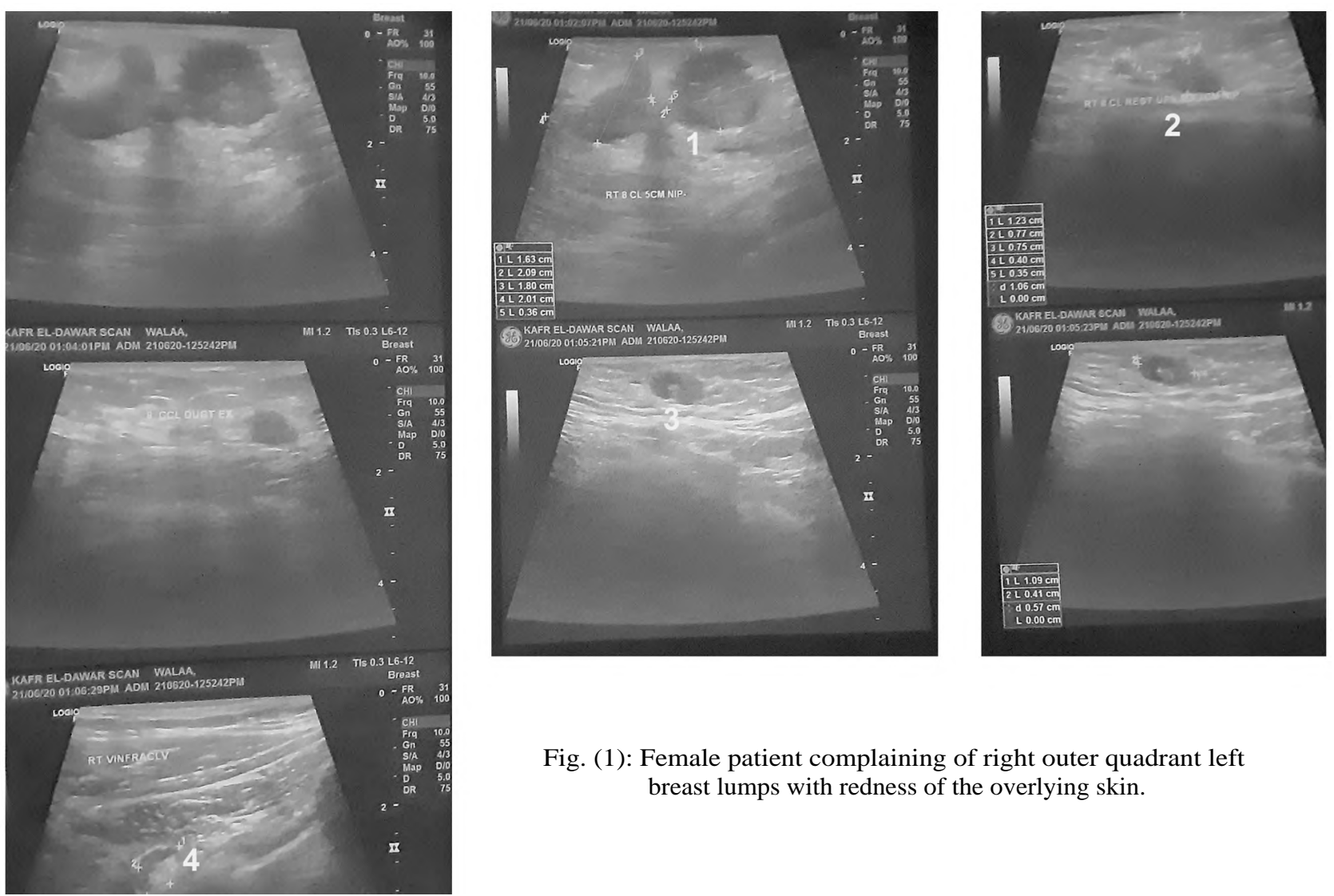

Fig. (1): Female patient complaining of right outer quadrant left breast lumps with redness of the overlying skin. 
The image of ultrasound shows:

- Two adjacent hypo echoic mass lesions measuring about $20 \times 16 \mathrm{~mm}$ and $20 \times 18 \mathrm{~mm}$ connected to each other by similar tissue (1).

- Another two hypo echoic smaller masses measuring $12 \times 7 \mathrm{~mm}$ and $7 \times 4 \mathrm{~mm}$ apart from each other (2).

- Hypoechoic mass lesion measuring 13 X 8mm exhibiting vertical orientation and microlobulated borders (3).

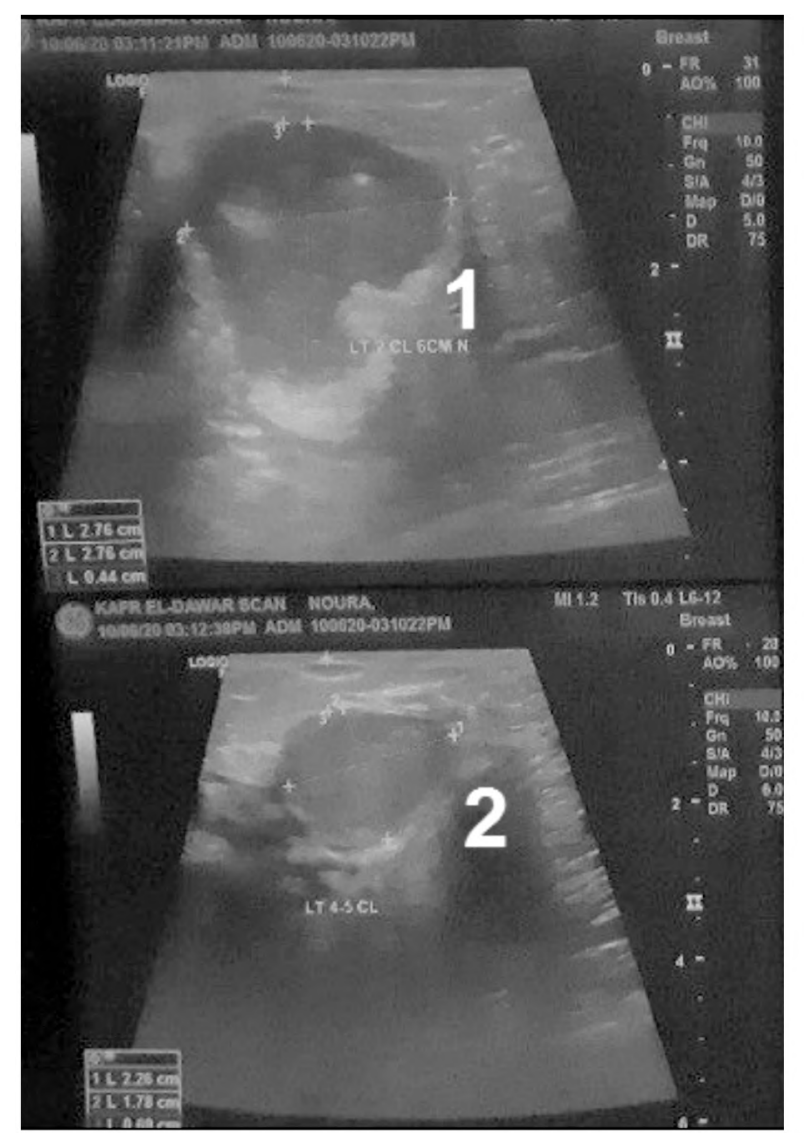

Fig. (2): Lactating female complaining of left breast painful lump with redness of the overlying skin.

The image of ultrasound shows:

- Loculated turbid fluid collection measuring about $2.7 \mathrm{~cm}$ surrounded by mild echogenic fat planes (1).

- Another turbid loculated collection is noted measuring $2.2 \times 1.7 \mathrm{~cm} \mathrm{(2).}$

- Prominent lactiferous ducts.

Features are impressive of galactoceles with impending abscess formation and surrounding mild inflammatory changes. The patient undergo clinical correlation and medical treatment with antibiotics. Follow-up after 4 weeks the breast show normal echopattern with no detected lesion.
- Tiny irregular hypoechoic mass lesion measuring 3 X $1 \mathrm{~mm}$.

- Two suspicious LNs show thickened cortices and eccentric hilum (4).

Features of right multi-centric suspicious mass lesions with axillary and infra-clavicular suspicious lymph nodes. Recommended for histopathological correlation which diagnose it as IDC.

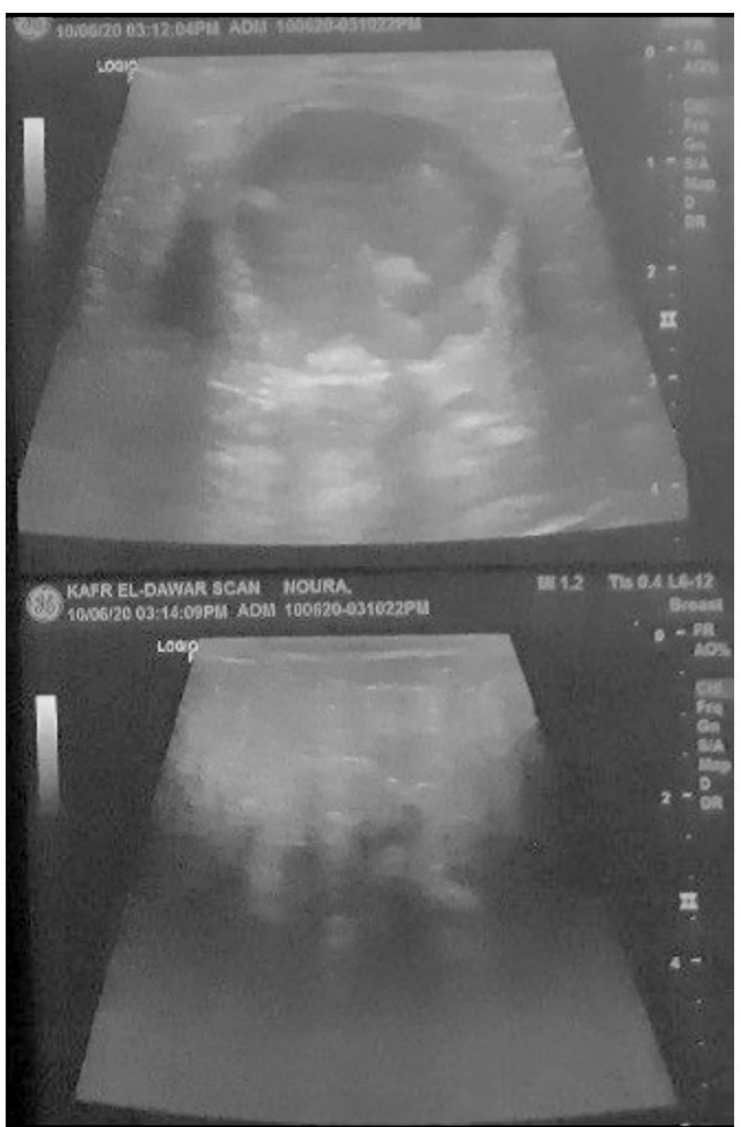


mastitis if after ten days of antibiotics symptoms of mastitis do not dissipate, inflammatory carcinoma should be ruled out and a biopsy should be performed [8].

IBC is an invasive aggressive disease with high rate of metastasis at diagnosis. It is crucial to differentiate IBC from other types of mastitis because there are major differences in its prognosis and treatment. Ultrasound (US) is one of the main diagnostic tools for discriminating benign and malignant mastitis [6].

On ultrasound, subareolar mastitis tends to show mixed solid-cystic lesions or collections, however, inflammatory breast cancers are more likely to show solid mass lesions. US-guided aspiration and core needle biopsy are the mainstay in diagnosis and management of inflammatory breast diseases $[8]$

Mastitis can be classified into three main types: The infectious, noninfectious, and Malignant Mastitis (MM). Infectious mastitis encompasses breastspecific and nonspecific forms of infections whether primary or complicating already present breast pathologies. This form of mastitis is more common during the child-bearing period especially during lactation. Patients in this group usually present with fulminant inflammatory manifestations and are usually treated with antibiotics, hot fomentations, and various breast drainage procedures [14]

Noninfectious forms of mastitis encompasses another group of aseptic or chemical inflammatory breast disorders that do not necessarily occur during lactation, and thus do not usually present with fulminant inflammatory signs and do not usually resolve with antibiotics. Microbial infection may trigger some forms as periductal mastitis or complicate others as diabetic mastopathy [15].

The third group of mastitis, which is the most serious form of mastitis, is malignant mastitis usually accompanying the Inflammatory Breast Carcinoma (IBC) or the very rare form of malignant breast abscess [15].

The aim of the current study was to discuss imaging findings in inflammatory breast disease by ultrasound.

This was a prospective study which was carried out at Ain Shams University Hospitals; the study was conducted on 100 women with inflammatory breast diseases referred to the Radiology Department and Surgical Outpatient's Clinics.
Ultrasound examination was performed to all cases and the findings were interpreted as regarding:

1- Echogenic edematous fat lobules.

2- Interstitial edema. Ill-defined collections.

3- Retro areolar duct system dilatation.

4- Thickened skin ( $>2 \mathrm{~mm}$ ) and its measurement.

5 - Masses and it confirm their cystic or solid nature.

6- Abscess cavities.

7- Fistulous tracts.

8- Lymph node enlargement and its status.

Lesions were classified according to the findings as benign and suspicious mastitis.

The findings were correlated eventually with the course of the disease either response to antibiotics till complete resolution and in this case diagnosed as benign mastitis or no response to the antibiotics with suspicious findings and in this case diagnosed as suspicious case and recommended for biopsy and histopathological examination.

Lymph nodes were also assessed according to size, shape, preserved hilum, cortical thickness and outlines regularity and classified into normal, reactive (oval in shape with preserved hilum and normal cortical thickness) and suspicious L.Ns (diffuse cortical thickness, eccentric hilum and distorted shape).

Analysis of our findings revealed that age of the participant women was ranged between 16.067.0 years with mean \pm S.D. $36.20 \pm 14.12$ years.

In the present study, we found that $73(73.0 \%)$ women were non lactating and $27(27.0 \%)$ women were lactating, then as regard echogenic edematous fat lobules; $30(30.0 \%)$ were negative and $70(70 \%)$ were positive, interstitial edema; 24 (24.0\%) were negative and $76(76 \%)$ were positive, defined collections; $68(68.0 \%)$ were negative and $32(32 \%)$ were positive.

In comparison with our findings, the study of Fouad et al., [16] reported that the presence of acute inflammatory signs on ultrasound (edematous, echogenic fat lobules and interstitial edema) could significantly differentiate infectious and malignant forms of mastitis $(p<0.05)$. Dilated ducts are significantly higher in non-infectious than infectious and malignant mastitis $(p<0.05)$ are significant differentiating signs between infectious and malignant mastitis. Mass lesions favor noninfectious and malignant forms of mastitis ( $p: 0.038$ and $p$ 0.023 ) over infectious forms. Thickened skin was 
significantly higher in malignant than infectious and non-infectious mastitis ( $p: 0.01$ and $p<0.05)$, dilated ducts are significantly higher in noninfectious than infectious and malignant mastitis $(p<0.05)$.

In the current study, retro areolar duct system dilatation of the studied cases was negative in 44 (44.0\%) and positive in $56(56.0 \%)$, then as regard the content; $80 \%$ has no turbid content, and $20 \%$ has a turbid content, also $52.0 \%$ had no thickened skin, while $48 \%$ had thickened skin.

Tiu et al., [17] reported that about four-fifths of patients with ductal dilatation were noted to have multiple dilated ducts, most commonly bilateral. The diameters of the ducts investigated ranged from $2.0 \mathrm{~mm}$ to $15 \mathrm{~mm}$, but most were between $2.0 \mathrm{~mm}$ and $4.0 \mathrm{~mm}$. The majority of them were anechoic or associated with very weak internal echoes $(90.8 \%)$. In about $8.5 \%$, there were formed echogenic structure(s) or nodule(s) in the lumen, and there were tiny strongly echogenic spots in the lumen representing calcified material, crystals or microcalcifications in $1 \%$. When the echogenic nodule in a dilated duct was located in the subareolar region, the focal lesion was most likely due to intra-ductal papilloma (52.9\%), and occasionally due to intra-ductal carcinoma (5.9\%).

Interestingly, in our study; abscess cavities and fistulous tracts of the studied group showed that at as regard abscess cavities; 53(53.0\%) were negative and $47(47.0 \%)$ were positive, and as regard fistulous tracts; $100(100.0 \%)$ were negative.

In contrary to our findings, the study of Fouad et al., [16] revealed that nine fistulous tracts with draining skin sinuses were being traced on ultrasound examination. Seven were seen draining neglected abscess cavities. Multiple discharging fistulous tracts were traced in a tuberculous patient and another one was seen draining a malignant abscess.

In the study on our hands; there were 93 (93.0\%) were negative masses and $7(7.0 \%)$ were positive Masses. The positive cases was divided as 3 $(42.9 \%)$ as irregular solid retro-areolar lesion masses, $3(28.6 \%)$ as multiple solid showing irregular outlines masses and $3(28.6 \%)$ as solid lesion irregular margins and internal breakdowns masses.

In the study done by Oztekin et al., [18], US showed heterogeneous hypoechoic lesions with tubular extensions in $16(55.2 \%)$, well-demarcated heterogeneous hypoechoic lesions in eight (27.6\%), parenchymal heterogeneous appearance in three
$(10.3 \%)$, and a heterogeneous hypoechoic lesion with irregular margins in one (3.4\%), with another (3.4\%) patient having normal US findings, meanwhile, the author reported that sixteen (55.2\%) patients had ill-defined lesions with tubular extensions, eight (27.6\%) had well-demarcated lesions with posterior acoustic enhancement, three $(10.3 \%)$ had parenchymal edema-heterogeneity, one (3.4\%) had a mass lesion with irregular borders, and one (3.4\%) had normal results. All lesions exhibited heterogeneous hypoechogenicity. Three (10.3\%) had fistula tracts.

Another study of Yildiz et al., [19] reported that US showed multiple irregular hypoechoic masses and collection areas with tubular connections in 25 of 30 . The collection area with low-level internal echoes but without tubular connections, suggesting an abscess were seen in 2 of $30(6.6 \%)$; a hypoechoic mass with an indistinct border in 2 of 30 (6.6\%); multiple milimetric hypoechoic nodular masses in 1 of $30(3.3 \%)$. On MG, normal findings were noted in $5(45.4 \%)$; focal asymmetric density in $4(36.4 \%)$, parenchymal distortion in $1(9 \%)$ and diffuse asymmetric opacity with trabecular thickening in $1(9 \%)$ of 30 patients.

In the current study, lymph node enlargement of the studied group showed that $54(54.0 \%)$ were negative and $46(46.0 \%)$ were positive. There was lymph node enlargement for only 45 (31 cases show reactive lymph nodes oval in shape with preserved shape and hilum and 14 cases show suspicious lymph nodes with cortical thickening and eccentric hilum).

Bilgen et al., [20], in their study, diagnosed metastatic enlarged lymph nodes when they showed eccentric or absent hila and when the long to short axis ratio was less than 1.5.

Kamal et al., [14] found that lymph nodes with these criteria were higher in IBC, a sign that favored its diagnosis.

Aziz et al., [6] reported that in benign inflammatory cases; the presence of indeterminate axillary lymph nodes was $6 / 10,60 \%$, the presence of nonspecific axillary lymph nodes was $29 / 30,96.7 \%$, and the presence of pathological axillary lymph nodes was $1 / 8,12.5 \%$, while in malignant cases; the presence of indeterminate axillary lymph nodes was $4 / 10,40 \%$, the presence of nonspecific axillary lymph nodes was $1 / 30,3.3 \%$, and the presence of pathological axillary lymph nodes was $7 / 8,87.5 \%$. The presence of pathological axillary lymph nodes with prominent cortices and muffled hila was strongly indicative of a malignant pathology. Inde- 
terminate axillary lymph nodes were a common association with severe benign mastitis. Resolution was the rule on follow-up US studies performed in $6 / 10(60 \%)$ cases.

In the present study, follow-up by $\mathrm{u} / \mathrm{s}$ and histopathology of the studied group showed that 93 (93.0\%) were resolved and 7 (7.0\%) were IDC by histopathology.

Aziz et al., [6] demonstrated that within the examined group, 40/48 (83.3\%) cases underwent short-term first look follow-up US study after a course of antibiotic therapy, a total of seven out of $40(17.5 \%)$ patients showed complete resolution of the symptoms, and the diagnosis of simple IM was confirmed, in addition, 33 out of $40(82.5 \%)$ patients showed no response to treatment.

Radiographic studies of Cheng et al., [21] showed that $64 \%$ patients had abnormal findings suggesting a neoplastic process. Tissue biopsy and histologic examination are required to establish a definitive diagnosis. Six categories of mastitis can be seen with distinct histopathological features.

According to Fouad et al., [16] and ultrasound findings, $83(42.2 \%)$ cases were re-assured and were given a short course of antibiotic therapy and hot fomentations. These included 46 (23.3.\%) cases of simple mastitis, 32 (16.3\%) cases of periductal mastitis and 5 (2.6\%) cases of plasma cell mastitis. They were asked to come for a short term followup study to ensure complete resolution. Complicated mastitis cases (77 cases, 39.1\%) were drained, given a course of antibiotic therapy and were asked to come for a short term follow-up ultrasound study to ensure complete resolution.

Finally in the present study, we found that the ultrasonography imaging sensitivity was $82.3 \%$, specificity was $90.7 \%$, NPV was $87.7 \%$ and PPV was $87.6 \%$ with accuracy of $90 \%$ to assess for respectability.

In agreement with our findings, the study of Aziz et al., [6] reported that out of the 48 cases included in the study, US results showed the following: Two false negative (4.2\%), two false positive $(4.2 \%), 34$ true negative $(70.8 \%)$, and 10 true positive $(20.8 \%)$ cases. The calculated sensitivity and specificity of US are 83.33 and $94.44 \%$, respectively. The positive predictive value for US was $83.33 \%$ and the negative predictive value was $94.44 \%$.

To sum up, ultrasound examination is gold standard breast imaging technique in inflammatory breast disorders because it is a non-invasive, rapid bedside method, carry no recognized risks or side effects and are not known to cause or aggravate any medical condition and safe in pregnancy.

It should be considered the mainstay in making an accurate diagnosis, in monitoring treatment and in guiding interventional procedures.

Yet one must put in consideration the overlap between benign and malignant lesions and so reaching full diagnosis sometimes may not be achieved until histopathological verification.

\section{Conclusion:}

Ultrasound plays a fundamental role in the diagnostic work up of mastitis patients. An ideal ultrasound should ensure an accurate diagnosis, guide for interventional procedures whenever necessary and should be used to monitor adequate management by short term follow-up studies along the course of therapy.

\section{References}

1- LEPORI D.: Inflammatory breast disease: The radiologist's role. Diagn. Interv. Imaging, 96: 1045-64, 2015.

2- KASALES C.J., HAN B., SMITH J.S. Jr., CHETLEN A.L., KANEDA H.J. and SHEREEF S.: Nonpuerperal mastitis and subareolar abscess of the breast. Am. J. Roentgenol., 202: 133-9, 2014.

3- TOHAMEY Y.M. and OMAR O.S.: Integration of magnetic resonance imaging in characterization of inflammatory breast disorders. The Egyptian Journal of Radiology and Nuclear Medicine, 49 (4): 1190-7, 2018.

4- ILLMAN J.E., TERRA S.B., CLAPP A.J., HUNT K.N., FAZZIO R.T., SHAH S.S. and GLAZEBROOK K.N.: Granulomatous diseases of the breast and axilla: Radiological findings with pathological correlation. Insights into imaging, 9 (1): 59-71, 2018.

5- LEONG P.W., CHOTAI N.C. and KULKARNI S.: Imaging features of inflammatory breast disorders: A pictorial essay. Korean journal of radiology, 19 (1): 5-14, 2018.

6- AZIZ A.A., KAMAL R.M. and MOHAMMED R.S.: Role of ultrasound in diagnosis and management of inflammatory breast diseases. The Egyptian Journal of Surgery, 37 (1): 122-31, 2018.

7- IRAKLEIDIS F. and TAN P.H.: Inflammatory Breast Cancer; Diagnostic and Therapeutic Challenges. Therapy, 2 (1), 126, 2019.

8- GUNAWARDENA R.P., GUNAWARDENA D., METCALF C., TAYLOR D. and WYLIE L.: Inflammatory breast disease: A pictorial essay with radiologicalpathological correlation. Journal of medical imaging and radiation oncology, 61 (1): 70-6, 2017.

9- DARLINGTON A.J.: Anatomy of the breast. In Digital Mammography (pp. 3-10). Springer, Cham., 2015. 
10- FEBERY A. and BENNETT I.: Sonographic features of inflammatory conditions of the breast. Australasian Journal of Ultrasound in Medicine, 22 (3): 165-73, 2019.

11- CRANE E., UKEH I.M. and LEWIS N.S.: Nonneoplastic Inflammatory Conditions of the Breast. Contemporary Diagnostic Radiology, 40 (21): 1-7, 2017.

12- FAGUY K.: Infectious and inflammatory breast disease. Radiologic technology, 89 (3): 279-95, 2018.

13- SABATÉ J., CLOTET M.G., ANTONIO H., PILAR T. and SOFIA S.: Radiologic Evaluation of Uncommon Inflammatory and Reactive Breast Disorders1. Radiographics: A review publication of the Radiological Society of North America, Inc., 25: 411-24, 2005.

14- KAMAL R., HAMED S. and SALEM D.: Classification of Inflammatory Breast Disorders and Step by Step Diagnosis. The Breast Journal, 15: 367-80, 2009.

15- BOAKES E., WOODS A., JOHNSON N. and KADOGLOU N.: Breast infection: A review of diagnosis and management practices. European journal of breast health, 14 (3): 136, 2018.

16- FOUAD R., HAMED S.T., SALEM D., MANSOUR S.A. and ADEL L.: Role of ultrasound in the management of Mastitis: When to re-assure, when to follow-up and when to interfere? 10.1594/ecr2012/C-0324.
17- TIU C.M., SEE-YING CHIOU, YI-HONG CHOU, CHIHYI HSU1, CHIOU-HSIN LAI, HONG-JEN CHIOU, HUIRU CHIANG, SIEW-PENG CHEN, HSIN-KAI WANG, CHAO-SHUEN YEN and CHENG-YEN CHANG: Clinical Significance of Ductal Dilatation on Breast Ultrasonogram, J. Med. Ultrasound, 13 (3): 127-34; J. Med. Ultrasound, Vol. 13, No. 3, 2005.

18- OZTEKIN P.S., DURHAN G., KOSAR P.N., EREL S. and HUCUMENOGLU S.: Imaging findings in patients with granulomatous mastitis. Iranian Journal of Radiology, 13 (3), e33900, 2016.

19- YILDIZ S., ARALASMAK A., KADIOGLU H., TOPRAK H., YETIS H., GUCIN Z. and KOCAKOC E.: Radiologic findings of idiopathic granulomatous mastitis. Med. Ultrason., 17 (1): 39-44, 2015.

20- BILGEN I.G., USTUN E.E. and MEMIS A.: Fat necrosis of the breast: Clinical, mammographic and sonographic features. Eur. J. Radiol., 39: 92-9, 2001.

21- CHENG L., VIJAYA REDDY, GENE SOLMOS, LATANJA WATKINS, DAVID CIMBALUK, PINCAS BITTERMAN, RITU GHAI, and PAOLO GATTUSO: Mastitis, a Radiographic, Clinical, and Histopathologic Review, DOI: 10.1111/tbj.12430 () 2015 Wiley Periodicals, Inc., 1075-122X/15 The Breast Journal, Volume 21 Number 4: 403-9, 2015.

\section{تقييم نتائج التصوير فى آمراض الثدى الإلتهابية بالموجات فوق الصوتية}

يشير إلتهاب الثدى إلى إلتهاب نسيج الثدى، وغالباً ما يظهر مع الآلم والحرارة والإحمرار الذى قد يكن مرضاً موهناً بمراضة طويل الآمد.

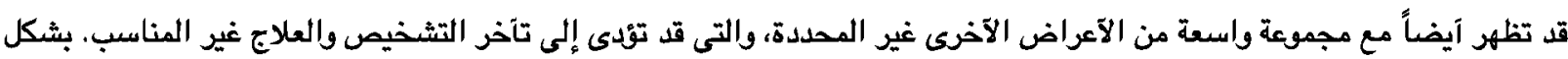

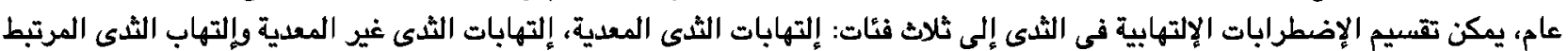
بالآوارم الخبيثة الكامنة.

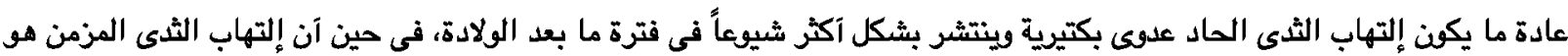

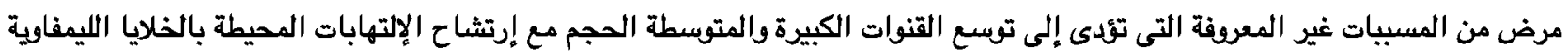

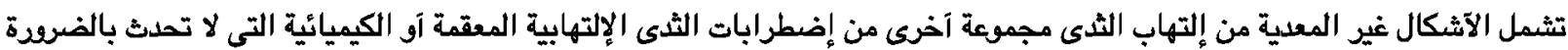

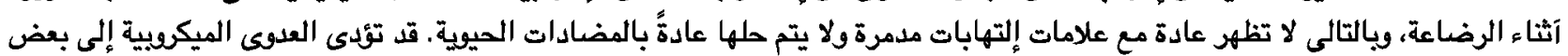
الآثكال مثل إلتهاب الثدى حل الجافية آو تعقيد الآثكال الآخرى مثل إعتلال الخاء الخشاء السكرى.

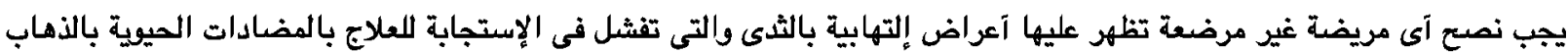

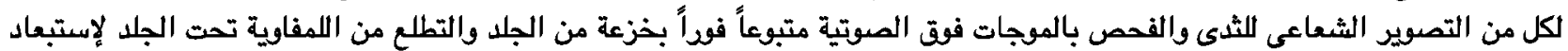
آى إحتمال لصدوث إلتهاب الثىى المرتبط بالآورام الخبيثة.

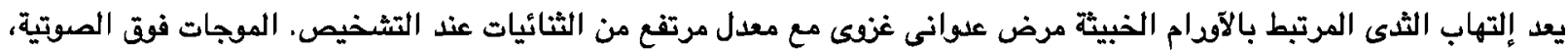

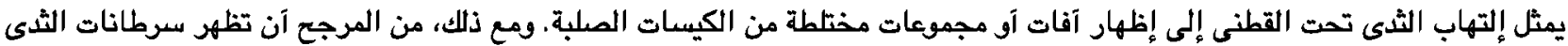
الإلتهابية آنات كتلة صلبة. 
يعد فرط الدم (زيادة الآوعية الدموية) فى آنسجة الثدى علامة آخرى على الإلتهاب. يمكن تقييم ذلك بإستخدام الموجات فوق الصوتية، للكثف عن زيادة الهياكل الشريانية والوريدية.

يجب فحص شذوذ القناة اللبنية مثل توسع القناة والجدران السميكة وقجود المحتويات داخل القنوات حيث ترتبط بعض الحفالات الإت الإلإتهابية

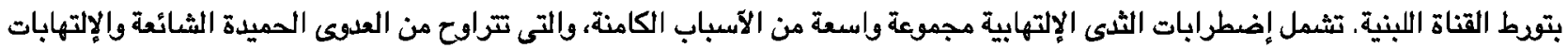

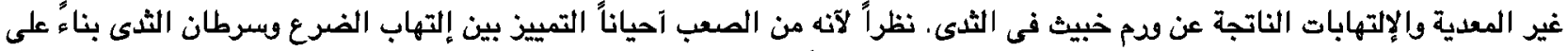

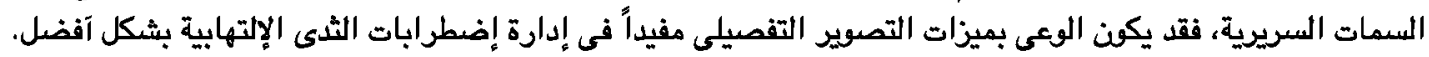

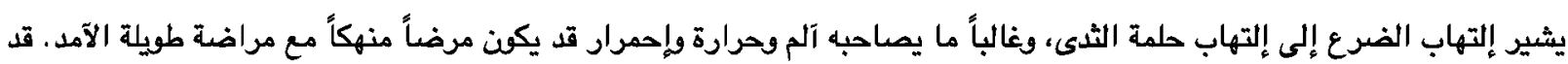

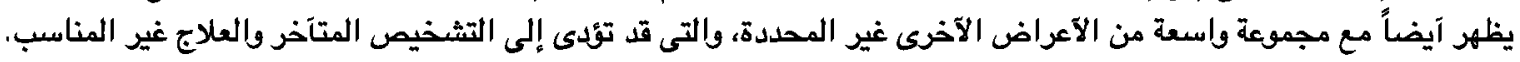

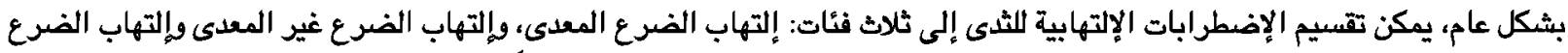

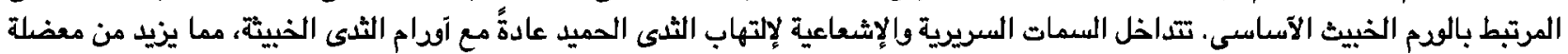

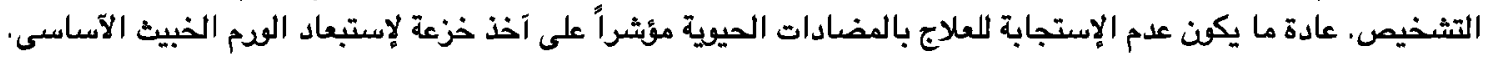

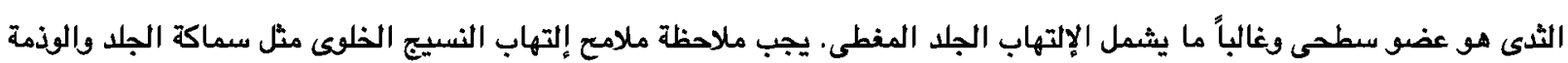

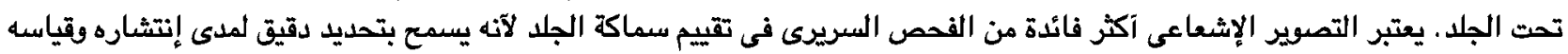
ومقارنته بالجلد المحيط والثدى المقابل.

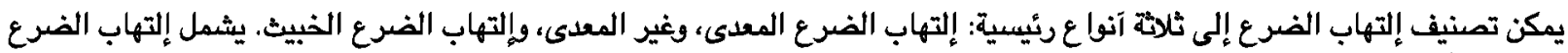

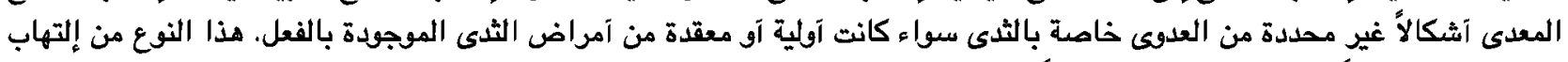

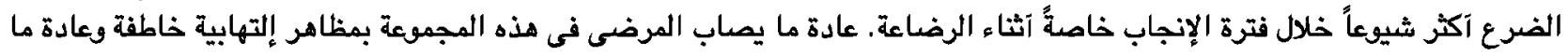

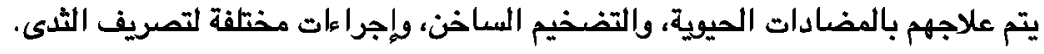

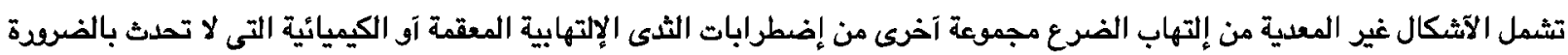

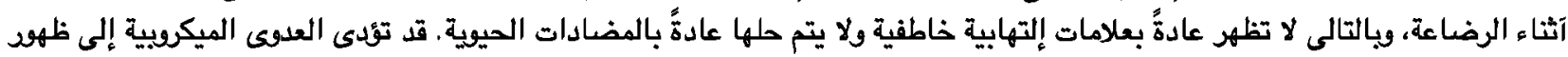

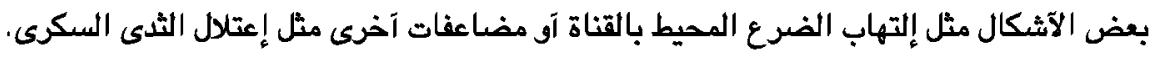

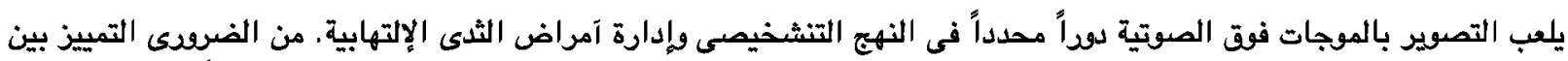

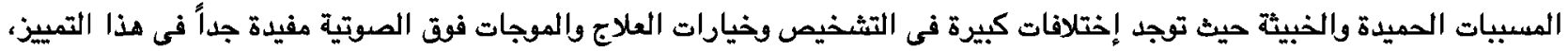

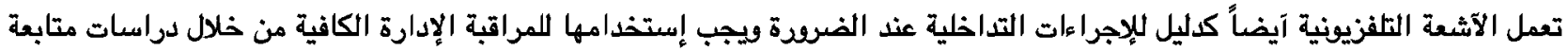
قصيرة المدى على طول مسار العلاج.

الهدف من الدراسة الحالية هو مناقشة نتائج التصوير فى مرض إلتهاب الثدى عن طريق الموجات فوق الصوتية. كانت هذه دراسة إستطلاعية آجريت فى مستشفيات جامعة عين شمس. آجريت الدراسة على . ـ إمرآة مصابة بآمراض الثدى الإلتهابية المحولة إلى قسم الآشعة وعيادات الجراحة الخارجية. 